\title{
A EXPLORAÇÃO DO TRABALHO INFANTIL NO BRASIL E A ATUAÇÃO DO MINISTÉRIO PÚBLICO EM AÇÕES DE DIREITOS DIFUSOS, COLETIVOS E INDIVIDUAIS HOMOGÊNEOS
}

\author{
MAGNO LUIZ BARBOSA*
}

\author{
[...] grande é a poesia, a bondade e as danças... \\ Mas o melhor do mundo são as crianças [...].
}

(Fernando Pessoa)

\begin{abstract}
RESUMO: Este trabalho tem como objetivo fazer uma abordagem da exploração do trabalho infantil no Brasil, versando sobre a questão da idade mínima - prevista na Constituição Federal de 1988 e alterada pela Emenda Constitucional 20/98 - a atuação da Organização Internacional do Trabalho - OIT e do governo brasileiro na tentativa de erradicação desse tipo de exploração e as ações concretas do Ministério Público do Trabalho para fazer cumprir a legislação que norteia o assunto. Para tanto, será feito um estudo legislativo, doutrinário e jurisprudencial acerca do tema. Com isso, busca-se aguçar a reflexão em torno dessa situação tão grave e ao mesmo tempo tão constante em nosso País. PALAVRAS-CHAVE: Trabalho infantil; Justiça Social; Criança; Adolescente; OIT; Ação Civil Pública; Ministério Público; Contrato de Trabalho.
\end{abstract}

ABSTRACT: The objective of this work is to analyse the exploitation of child labor in Brazil, dealing with the subject of minimum age - included in the 1988 Federal Constitution and altered by the 20/98 Constitutional Amendment, the work of the International Labor Organization (ILO) and of the Government of Brazil, in their attempts to eradicate this sort of exploitation and the concrete actions taken by the Federal Labor Prosecution (Ministério Público do Trabalho) to enforce the legislation concerning child labor. In order to achieve these goals, a study regarding the legislative and jurisprudential aspects of the theme, besides the doctrine, will be done. The intention is to improve the reflection about this situation, which is at the same time so grave and so constant in Brazil. KEYWORDS: Infantile Work; Social Justice; Child; Teenager; I.L.O.; Public Civil Action; Public Ministry; Labor Agreement.

SUMÁRIO: Introdução; 1. A legislação protetora das crianças e adolescentes no Brasil; 2. O trabalho infantil e os elementos essenciais à formação do contrato de trabalho;

Artigo recebido em 27.09.2010. Pareceres emitidos em 23.12.2010 e 16.12.2010.

Artigo aceito para publicação em 6.01.2011.

* Doutorando em Direito das Relações Sociais pela Pontifícia Universidade Católica de São Paulo - PUC/SP. Mestre em Direito das Relações Econômico-Empresariais pela Universidade de Franca (2005) - UNIFRAN. Especialista em Direito Civil (1999) e Direito Processual Civil (1998), pela Universidade Federal de Uberlândia - UFU. Graduado em Direito no ano de 1997. Professor de Direito do Trabalho e Direito Processual do Trabalho da Universidade Federal de Uberlândia - UFU e da Faculdade Pitágoras de Uberlândia/MG. 
3. Os problemas sociais e a exploração do trabalho infantil; 4. A atuação da OIT e do Brasil quanto ao trabalho infantil; 5. Atribuições e atuação administrativa do Ministério Público em relação à proteção a crianças e adolescentes; 6. Atuação do Ministério Público em casos concretos; Conclusões; Bibliografia.

SUMMARY: Introduction; 1. The legislation protecting children and adolescents in Brazil; 2. Child labor and the essential aspects of the work contract; 3. The social problems and the exploitation of child labor: 4. Brazil and ILO work on child labor; 5. Attributions and administrative work of the Public Prosecutions Office on children and adolescents protection: 6. Work of the Public Prosecutions Office on concrete cases; Conclusions; Bibliography.

\section{INTRODUÇÃO}

O tema proposto tem como escopo trazer à baila a situação atual da exploração do trabalho infantil no Brasil e as ações judiciais do Ministério Público do Trabalho visando à proteção das crianças e adolescentes brasileiros. Há que se fazer uma abordagem acerca do Direito do Trabalho aplicado à questão do desemprego, à promoção da cidadania e à dignidade da pessoa humana. Para tanto, serão abordadas as questões sobre o valor social do trabalho e o paradoxo da especulação financeira; a flexibilização e desregulamentação da legislação laboral apresentadas como possíveis instrumentos de combate ao desemprego juvenil; a justiça social a partir da conquista e efetivação dos direitos sociais; e, finalmente, verificar a eficiência das políticas públicas concernentes ao direito do trabalho infanto-juvenil.

A legislação brasileira relativa à regulamentação do trabalho infantil apresenta vários dispositivos que enunciam a obrigatoriedade de proteger os direitos da criança e do adolescente, a começar pela Carta Magna de 1988 que estabelece, dentro das Garantias Fundamentais do Cidadão, no Capítulo II “Direitos Sociais”, a permissão do trabalho de jovens a partir dos 14 anos, na condição de aprendiz (art. $7^{\circ}$, inciso XXXIII). Muito bem observa Cláudia Salles Vilela Viana no que se refere ao responsável legal do menor de que, conforme o Código Civil (art. $5^{\circ}$, parágrafo único, inciso V), ao autorizar a relação de emprego estará automaticamente concedendo ao menor o instituto legal da emancipação ${ }^{1}$ que permitirá o exercício amplo da cidadania. Amplia-se este conceito para "cidadania social”, nas palavras de Marcos Francisco Reimann, que mostra tê-la no trabalho e na seguridade social o seu principal substrato. "Para a imensa maioria da população, o trabalho é o mais importante, senão o único, caminho para a inserção social e o exercício da cidadania”².

Não há dúvidas de que o trabalho está diretamente relacionado à dignidade da pessoa humana, pois, por meio dele, o cidadão desenvolve perspectivas de melhoria da sua condição social, garante a sua sobrevivência e a de sua família, enfim, tem possibilidade de construir e realizar os seus sonhos. Entretanto, a discussão em questão visa abordar o outro lado da moeda, ou seja, a exploração do trabalho de crianças e

${ }^{1}$ VIANA, Cláudia Salles Vilela. Manual de Prática das Relações Trabalhistas. 5 ed., São Paulo: LTr, 2005, p. 278-279.

${ }^{2}$ REIMANN, Marcos Francisco. Cidadania e contratos atípicos de trabalho: as políticas sociais e o ordenamento do trabalho. Porto Alegre: Sergio Antonio Fabris Editor, 2002, p. 96. 
jovens, que muitas vezes ocorre em condições subumanas que indubitavelmente destroem a dignidade da pessoa humana.

É imprescindível salientar que não há, no presente estudo, a pretensão de esgotar o assunto que, no mínimo, seria absurda. Espera-se apenas que esta reflexão possa, de alguma forma, colaborar, se não para o entendimento mais amplo do tema, pelo menos no aprofundamento do debate sobre este assunto de extrema relevância social.

\section{NO BRASIL}

1. A LEGISLAÇÃO PROTETORA DAS CRIANÇAS E ADOLESCENTES

Uma das mais antigas e desumanas formas de trabalho subordinado é a escravidão, que se resume na prática social no fato de uma pessoa possuir direitos de propriedade sobre outro indivíduo, designado escravo, condição imposta pela força.

Indubitavelmente a escravidão é a forma mais execrável de exploração do trabalho humano. No caso específico das crianças do Brasil, a proteção contra esse tipo de trabalho começou a ser combatida legalmente em 1871, com a promulgação da Lei $\mathrm{n}^{\circ}$ 2.040, que ficou conhecida como Lei do Ventre Livre, segundo a qual toda criança, filha de escrava, que nascesse a partir daquela data não era mais escrava; a mãe continuava escrava, mas a criança era livre.

Em 13 de maio de 1888, foi promulgada a Lei Áurea, que previa a libertação de todos os escravos no Brasil, o que infelizmente não ocorreu, pois se sabe que até os dias atuais a luta é constante para erradicação do trabalho escravo no País e no mundo.

Logo em seguida, em 1891, entrou em vigor o Decreto 1.313 que estabeleceu uma série de medidas com o objetivo diminuir a exploração do trabalho infantil, proibindo, por exemplo, que crianças com menos de 12 anos trabalhassem como empregadas nas fábricas de tecido, salvo como aprendiz, condição permitida para crianças entre oito e 12 anos de idade. O Decreto previa também a jornada de trabalho máxima de sete horas por dia para os menores do sexo feminino, com idade entre 12 e 15 anos, e para os do sexo masculino a faixa etária para essa jornada de trabalho era entre sete e 14 anos. Por esse mesmo Decreto, ficava proibido que menores de ambos os sexos, até 15 anos de idade, trabalhassem aos domingos e feriados nacionais, bem como em horário noturno - aquele compreendido entre as 18 horas de um dia e as 6 horas da manhã do dia seguinte.

Segundo Santos Minharro ${ }^{3}$, o Decreto 1.313 jamais foi regulamentado e suas diretrizes não foram efetivamente colocadas em prática. A autora também comenta que a Constituição da República de 24 de fevereiro de 1891, de inspiração liberal abstencionista, não tratava de questões relacionadas ao trabalho (muito menos ao infanto-juvenil).

Em 1927, foi promulgado o Primeiro Código de Menores da América Latina, cujo capítulo IX tratava do labor infanto-juvenil, expressando, dentre outras proibições, o trabalho de menores de 12 anos de idade em todo território nacional (art. 101).

${ }^{3}$ MINHARRO, Erotilde Ribeiro dos Santos. A criança e o adolescente do Direito do Trabalho. São Paulo: LTr, 2003, p. 24. 
Quanto ao Decreto $\mathrm{n}^{\circ}$ 17.943-A, Rodello ${ }^{4}$ lembra que um habeas corpus suspendeu a entrada dele em vigor por dois anos, alegando que atentava contra o direito dos genitores decidirem o que era melhor para os filhos.

A preocupação com a questão da idade mínima para o início da vida laboral continuou em voga na Constituição Federal de 1934 que, no art. 121, § 1º, “d”, proibia o trabalho de menores de 14 anos, o que foi mantido no art. 137, "k” da Constituição de 1937.

Contudo, pode-se dizer que um grande passo na legislação de proteção contra a exploração do trabalho infantil ocorreu em 1943 quando, na Era Vargas, entrou em vigor a Consolidação das Leis do Trabalho-CLT -, por meio do Decreto-Lei $n^{\circ} 5.452$, que reservou o Capítulo IV à proteção do trabalho do menor, especificando do artigo 402 ao 441, as normas especiais de tutela e proteção ao trabalho infanto-juvenil.

Ainda na ânsia de se alcançar uma forma efetiva de proteção contra a exploração do trabalho infantil, em 1964 foi promulgada a Lei ${ }^{\circ}$ 4.513, que instituiu a Política Nacional do Bem-Estar do Menor, posteriormente revogada pela Lei ${ }^{\circ}$ 8.069/90.

Em 1979, foi instituído o novo Código de Menores, por meio da Lei n ${ }^{\circ} 6.697 / 79$, a qual não acrescentou nada de significativo na legislação já existente, visto que o art. 83 dispõe que “a proteção ao trabalho do menor é regulada por legislação especial”.

Em 1988, sob a égide do regime democrático, foi promulgada a Carta Magna Brasileira, chamada de "Constituição Cidadã”, que traz como um de seus pilares a Dignidade da Pessoa Humana que, mais que um princípio, é a razão de ser do Direito, como bem leciona o Professor Nelson Nery Jr.:

Esse princípio não é apenas uma arma de argumentação, ou uma tábua de salvação para a complementação de interpretações possíveis de normas postas. Ele é a razão de ser do Direito. Ele se bastaria sozinho para estruturar o sistema jurídico ${ }^{5}$.

Somente esse fundamento seria suficiente para a proteção contra a exploração de qualquer trabalho degradante, principalmente no que diz respeito ao trabalho infantil. Contudo, outros artigos da Constituição de 1988, que versam especificamente sobre a proteção à criança e ao adolescente, merecem destaque por sua completude, como por exemplo, o art. 227, § $3^{\circ}$ e incisos:

Art. 227. É dever da família, da sociedade e do Estado assegurar à criança e ao adolescente, com absoluta prioridade, o direito à vida, à saúde, à alimentação, à educação, ao lazer, à profissionalização, à cultura, à dignidade, ao respeito, à liberdade e à convivência familiar e comunitária, além de colocá-los a salvo de toda forma de negligência, discriminação, exploração, violência, crueldade e opressão.

\footnotetext{
${ }^{4}$ RODELLO, Fernanda Cavalcante Batista. A profissionalização do menor aprendiz e a sua inserção no mercado de trabalho. Síntese Trabalhista. 2005, v. 16, n. 188, FEV, p. 38.

${ }^{5}$ NERY JUNIOR, Nelson; NERY, Rosa Maria de Andrade. Constituição Federal comentada e Legislação Constitucional. 2. ed., São Paulo: Revista dos Tribunais, 2009, p. 151.
} 
$[\ldots]$

$\S 3^{\circ}$ - O direito a proteção especial abrangerá os seguintes aspectos:

I - idade mínima de quatorze anos para admissão ao trabalho, observado o disposto no art. $7^{\circ}$, XXXIII;

II - garantia de direitos previdenciários e trabalhistas;

III - garantia de acesso do trabalhador adolescente à escola;

O inciso XXXIII do art. $7^{\circ}$ da Constituição Federal, mencionado no art. 227, sofreu alteração pela Emenda Constitucional no 2, de 15 de dezembro de 1998, que restringiu o trabalho adolescente a partir dos 16 anos, salvo na condição de aprendiz a partir de 14 anos de idade.

Após o advento da Constituição Federal de 1988, foi promulgado o Estatuto da Criança e do Adolescente-ECA -, por meio da Lei $n^{\circ} 8.069$, de 13 de julho de 1990, que inclusive revogou o Código de Menores de 1979. O ECA reforça o texto constitucional em vários momentos, como no art. $4^{\circ}$ que praticamente é uma repetição do art. 227 da Carta Magna:

Art. $4^{\circ}$ É dever da família, da comunidade, da sociedade em geral e do poder público assegurar, com absoluta prioridade, a efetivação dos direitos referentes à vida, à saúde, à alimentação, à educação, ao esporte, ao lazer, à profissionalização, à cultura, à dignidade, ao respeito, à liberdade e à convivência familiar e comunitária.

No mesmo sentido, segue o art. $5^{\circ}$ do ECA que, além de repetir o disposto na Constituição Federal de 1988, reforça o disposto na Convenção sobre os Direitos da Criança, adotada pela Assembléia Geral das Nações Unidas em 20 de novembro de 1989, ratificada pelo Brasil em 24 de setembro de 1990, entrando em vigor no País em 23 de outubro de 1990 e sendo promulgada em 21 de novembro de 1990, por meio do Decreto no 99.710 .

Art. $5^{\circ}$ Nenhuma criança ou adolescente será objeto de qualquer forma de negligência, discriminação, exploração, violência, crueldade e opressão, punido na forma da lei qualquer atentado, por ação ou omissão, aos seus direitos fundamentais.

Percebe-se que o artigo em destaque é praticamente uma réplica do art. 19 da Convenção sobre os Direitos da Criança, que prevê que os Estados deverão tomar todas as medidas úteis à proteção da criança contra as formas de violência, brutalidade física ou mental, abandono ou negligência, maus tratos e muito mais. Essa Convenção prevê ainda medidas de intervenção judiciária contra os autores desses atos praticados contra o menor.

Na esteira da mencionada Convenção sobre os Direitos da Criança, o ECA também prevê a intervenção judiciária do Estado visando à proteção de crianças e adolescentes, por meio da atuação do Ministério Público, conforme se verifica no seu inciso V do art. 201:

Direitos Fundamentals $\mathcal{E}$ Justiça N' 13 - OUt./Dez. 2010 
Art. 201. Compete ao Ministério Público:

$[\ldots]$

V - promover o inquérito civil e a ação civil pública para a proteção dos interesses individuais, difusos ou coletivos relativos à infância e à adolescência, inclusive os definidos no art. 220, § $3^{\circ}$ inciso II, da Constituição Federal;

Há que se ressaltar que de acordo com o art. $6^{\circ}$ da Lei 8.242/91, quando ocorre a propositura de ações civis públicas pelo Ministério Público do Trabalho que versem sobre interesses da criança e do adolescente e que culminam em indenizações em dinheiro, os valores vão para Fundo Nacional para Criança e o Adolescente, diferente do que ocorre nas demais demandas coletivas, nas quais o dinheiro vai para o Fundo Geral de Interesses Difusos dos Lesados ${ }^{6}$, conforme previsão do art. 13 da Lei da Ação Civil Púplica-LACP.

Quanto à questão da dignidade da criança e do adolescente, o assunto foi particularmente tratado nos artigos 15 e 18 do ECA, o que por si só seria suficiente para respaldar ações contra a exploração do trabalho infanto-juvenil.

Art. 15. A criança e o adolescente têm direito à liberdade, ao respeito e à dignidade como pessoas humanas em processo de desenvolvimento e como sujeitos de direitos civis, humanos e sociais garantidos na Constituição e nas leis.

$[\ldots]$

Art. 18. É dever de todos velar pela dignidade da criança e do adolescente, pondo-os a salvo de qualquer tratamento desumano, violento, aterrorizante, vexatório ou constrangedor.

A preservação da dignidade trata-se de um princípio fundamental, inerente ao Estado Democrático de Direito. O menor, enquanto criatura humana e sujeito de direitos, deve ter garantido tratamento com respeito, que lhe garanta a preservação e fomentação de sua dignidade.

Com vistas ao que já está previsto na Constituição Federal, os artigos 15 e 18 poderiam até ser taxados de redundantes, contudo, a ênfase trazida pelo texto legal em destaque foi proposital, tendo em vista que o legislador visa garantir proteção específica a crianças e adolescentes.

Toda legislação aqui elencada demonstra uma preocupação indiscutível com a proteção plena à criança e ao adolescente, inclusive no que diz respeito à proteção contra a exploração do trabalho infanto-juvenil. Neste sentido, Paulo Garrido assevera que essa proteção plena busca "propiciar e garantir o desenvolvimento saudável e integridade à criança e ao adolescente" ${ }^{\text {, }}$, isto com vistas a sua condição especial de ser em pleno desenvolvimento físico e psicológico.

${ }^{6}$ MAZZILLI, Hugo Nigro. A defesa dos interesses difusos em juízo. 20. ed., São Paulo: Saraiva, 2007, p. 620.

${ }_{7}^{7}$ PAULA, Paulo Afonso Garrido de. Direito da criança e do adolescente e tutela jurisdicional diferenciada. São Paulo: RT, 2002, p. 27. 
O fato é que infelizmente toda esta legislação ora abordada está carregada de utopia, não sendo efetivamente aplicada, ou seja, ocorre uma clara dissonância entre o que prevê a legislação e nossa realidade hodierna.

2. O TRABALHO INFANTIL E OS ELEMENTOS ESSENCIAIS À FORMAÇÃO DO CONTRATO DE TRABALHO

O Código Civil Brasileiro prevê, no art. 104, a necessidade de elementos essenciais à formação do contrato de trabalho, sendo que o primeiro é a capacidade das partes que, no Direito do Trabalho, é a aptidão para exercício de atos da vida laborativa, ou seja, consiste na possibilidade de exercer, de forma pessoal e livre, as obrigações de que se é titular.

A realidade brasileira atual é de que o menor somente poderá trabalhar a partir dos 16 anos de idade, salvo na condição de aprendiz, a partir de 14 anos, conforme se verifica no art. $7^{\circ}$, inciso XXXIII da Constituição Federal, alterada pela Emenda Constitucional 20/98.

A redação atual do inciso XXXIII do art. $7^{\circ}$ da Carta Magna criou celeuma em alguns segmentos da sociedade, os quais defendem que a idade mínima para o trabalho deveria ser de 14 anos, independentemente de ser na condição de aprendiz, o que culminou na interposição da Ação Direita de Inconstitucionalidade - ADIn nº 2096-0, proposta pela Confederação Nacional dos Trabalhadores na Indústria-CNTI -, distribuída no Supremo Tribunal Federal em 05 de novembro de 1999.

Os adeptos dessa corrente defendem que a determinação legal atual encontra-se “em completo desacordo com a realidade brasileira, ofendendo, frontalmente, normas contidas na própria Lei Maior"8.

A questão é que a redação anterior, do inciso XXXIII do art. $7^{\circ}$ da CF, mantinha a previsão de Constituições anteriores, proibindo "o trabalho noturno, perigoso ou insalubre aos menores de dezoito anos e de qualquer trabalho a menores de quatorze anos, salvo na condição de aprendiz”.

O fato é que, de acordo com a redação original do referido dispositivo legal antes da Emenda Constitucional $n^{\circ}$ 20/98, o limite etário ficava em dissonância com tudo que se considera razoável na proteção dos direitos da criança e do adolescente, ou seja, não havia anteriormente um limite mínimo para o trabalho na condição de aprendiz, o que é inaceitável quando se busca efetivar o direito constitucional de proteção à dignidade humana.

Em contrapartida, o principal argumento da CNTI é no sentido de que a atual previsão legal encontrada na Constituição Federal "está extremamente afastada do panorama social e econômico brasileiro" e nessa esteira menciono as observações de Eduardo Gabriel Saad, que assim disserta sobre o assunto:

Está o inciso XXXIII, do art. $7^{\circ}$, da Lei Fundamental, tão afastado do nosso panorama social e econômico que sua observância, em todos os pontos do território nacional encontrará sérias dificuldades.

\footnotetext{
${ }^{8}$ Esse trecho encontra-se na petição inicial da ADIn nº 20/98, proposta pela Confederação Nacional dos Trabalhadores na Indústria.
}

Direitos Fundamentals $\mathcal{E}$ Justiça N' 13 - OUt./Dez. 2010 
Não nos surpreenderemos se agentes do poder público (tanto do Executivo como do judiciário), notadamente das regiões menos desenvolvidas do País, relutarem em punir um empresário por haver dado serviço a menor de idade inferior a 16 anos e cujo salário seja indispensável à alimentação de seu grupo familiar $^{9}$

Conforme se verifica na ADIn $\mathrm{n}^{\circ}$ 2096-0, proposta pela CNTI, a realidade brasileira impõe que adolescentes deveriam poder trabalhar até mesmo com a idade de 12 anos, porém, segundo a Conferação, para se adequar ao razoável, deve-se permitir pelo menos o trabalho de menores com idade a partir de 14 anos.

É inquestionável que a realidade social e econômica do Brasil impõe a grande maioria da população uma condição de miserabilidade que certamente obriga crianças e jovens buscar trabalho muito antes do que se entende como a idade razoável para o início de atividades laborais.

Entretanto, o fato é que não se pode legalizar uma situação que venha colidir com os princípios básicos de proteção à criança e ao adolescente, simplesmente para respaldar legalmente condutas ilícitas de exploração ao trabalho infanto-juvenil.

O que realmente se espera é que o Estado adote, de forma efetiva, políticas públicas que evitem a necessidade de crianças e jovens iniciar sua vida laboral tão cedo, o que decisivamente traz consequências devastadoras no futuro dessa camada da população.

Diante disso, os argumentos elaborados pela CNTI parecem não ir ao encontro com os anseios da sociedade moderna, muito menos com o entendimento do judiciário, haja visto que o Procurador Geral da República já se pronunciou na referida ADIn, com parecer no sentido do não conhecimento da ação e, caso ultrapassado esse óbice, pela sua improcedência.

Assim sendo, atualmente, a capacidade para contratar prevista no art. 104 do Código Civil Brasileiro é de 16 anos quando se trata de contrato de trabalho na condição de empregado, sendo que entre 16 e 18 anos o jovem deverá ser assistido por seus representantes legais em caso de demandas trabalhistas, e a sua capacidade plena somente será alcançada com 18 anos completos.

Em suma, tem-se que é, portanto, absolutamente incapaz para o trabalho o menor de 16 anos, salvo na condição de aprendiz, a partir dos 14 anos, sendo relativamente incapazes os menores entre 16 e 18 anos, pois poderão ser estes empregados com autorização do responsável legal. (art. 408 CLT)

Diante disso, a contratação de menores de 16 anos como empregados torna o contrato nulo de pleno direito, tendo em vista não estar presente um dos requisitos essenciais para formação do contrato de trabalho.

Contudo, é imprescindível observar que a legislação visa garantir a segurança, a dignidade, a formação física e psicológica da criança e do adolescente, e jamais poderia ser usada para prejudicar o cidadão que por algum motivo fosse levado ao mercado de trabalho antes da idade mínima prevista na legislação ora mencionada.

\footnotetext{
${ }^{9}$ Trabalho intitulado Emenda Constitucional - Ec n ${ }^{\circ}$ 20, publicado in LTr Suplemento Trabalhista, $\mathrm{n}^{\circ}$ 038/99.
} 
Destarte, quando se encontra na prática a exploração do trabalho de menores que possuem idade inferior ao previsto na legislação constitucional, os direitos destes jovens têm sido observados e garantidos em nossos tribunais, pois caso contrário estaria ocorrendo uma apologia a condutas ilegais, bem como se estaria "premiando" o empregador que contratasse menores de 16 anos como empregados. Observem-se algumas decisões acerca do tema:

PREVIDENCIÁRIO E CONSTITUCIONAL - DECLARATÓRIA RECONHECIMENTO DE TEMPO DE SERVIÇO - TRABALHADOR RURAL - MENOR DE IDADE - INÍCIO DE PROVA MATERIAL - PROVA TESTEMUNHAL - DESNECESSIDADE DE RECOLHIMENTO DAS CONTRIBUIÇÕES CORRESPONDENTES AO PERÍODO AVERBADO VERBA HONORÁRIA - 1. Demonstração simultânea do início de prova material e da prova testemunhal acerca do exercício das atividades rurícolas da parte autora. 2. A vedação ao trabalho do menor, constante do inciso XXXIII do art. $7^{\circ}$ da $C F / 88$, visa à sua proteção, mas não pode prejudicá-lo quanto à contagem de tempo de serviço para fins previdenciários se, de fato, ocorreu o exercício da atividade la borativa... ${ }^{10}$

PREVIDENCIÁRIO - APOSENTADORIA POR TEMPO DE SERVIÇO - TRABALHADOR RURAL - MENOR DE 14 ANOS - ART. $7^{\circ}$, INC. XXXIII DA CONSTITUIÇÃO FEDERAL - TRABALHO REALIZADO EM REGIME DE ECONOMIA FAMILIAR - COMPROVAÇÃO ATRAVÉS DE DOCUMENTOS DO PAI DO AUTOR - Divergência jurisprudencial demonstrada. Entendimento do artigo 255 e parágrafos, do Regimento Interno desta Corte. - A norma constitucional insculpida no artigo $7^{\circ}$, inciso XXXIII da Constituição Federal, tem caráter protecionista, visando coibir o trabalho infantil, não podendo servir, porém, de restrição aos direitos do trabalhador no que concerne à contagem de tempo de serviço para fins previdenciários. Tendo sido o trabalho realizado pelo menor a partir de 12 anos de idade, há que se reconhecer o período comprovado para fins de aposentadoria... ${ }^{11}$

TRABALHO DO MENOR - ANOTAÇÃO DA CTPS - DIREITOS TRABALHISTAS - Não obstante a proibição constitucional ao trabalho do menor (art. $7^{\circ}, \mathrm{XXXIII),} \mathrm{se} \mathrm{este} \mathrm{existiu,} \mathrm{impõe-se} \mathrm{assegurar} \mathrm{a} \mathrm{ele} \mathrm{todos} \mathrm{os} \mathrm{direitos}$ trabalhistas, não prevalecendo a alegação de que a nulidade do contrato de trabalho importaria a anulação das conseqüências legais da relação de emprego. Se o menor despendeu sua força de trabalho em prol de alguém que estava proibido de contratá-lo - Pois que é aos empregadores que a proibição é primeiramente dirigida - Não pode eximir-se das responsabilidades daí advindas, devendo arcar integralmente com a contraprestação devida, na forma da Lei. ${ }^{12}$ (Sic)

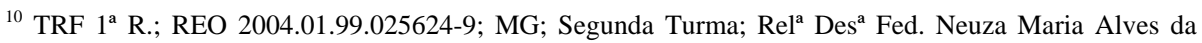
Silva; Julg. 26.05.2008; DJF1 14.08.2008; p. 39.

${ }^{11}$ STJ; RESP 541103; RS; Quinta Turma; Rel. Min. Jorge Tadeo Flaquer Scartezzini; Julg. 28.04.2004; DJU $1^{\circ} .07 .2004 ;$ p. 260

${ }_{12}$ TRT $3^{\text {a }}$ R.; RO 01373-2005-129-03-00-4; Primeira Turma; Rel. Juiz Marcus Moura Ferreira; DJMG 31.03.2006; p. 5.
} 
Ainda no que diz respeito à capacidade para ser contratado como empregado, há que se observar também a situação de crianças e jovens que trabalham em alguns tipos especiais de profissões que exigem que as atividades laborais se iniciem muito cedo, as vezes na infância, como é o caso dos artistas mirins.

Nesses casos específicos, a lei trabalhista prevê a permissão de autorização judicial para o trabalho, desde que observadas regras básicas de proteção à formação moral dessas crianças e jovens, conforme previsão no art. 406 da CLT:

Art. 406 - O Juiz de Menores poderá autorizar ao menor o trabalho a que se referem as letras "a" e "b" do $\S 3^{\circ}$ do art. $405^{13}$ :

I - desde que a representação tenha fim educativo ou a peça de que participe não possa ser prejudicial à sua formação moral;

II - desde que se certifique ser a ocupação do menor indispensável à própria subsistência ou à de seus pais, avós ou irmãos e não advir nenhum prejuízo à sua formação moral.

A partir do momento em que a legislação trabalhista prevê esse tipo de autorização judicial para o trabalho de crianças e jovens abaixo da idade mínima prevista na Constituição Federal, surgem questionamentos sobre qual juízo será competente para conceder a referida autorização: o juízo da vara especializada do trabalho ou o da justiça comum?

O Superior Tribunal de Justiça, bem como alguns Tribunais Regionais já se manifestaram sobre o tema, com decisões uníssonas, no sentido de que a competência é da justiça comum, por meio do juízo das varas da infância e juventude:

CONFLITO DE COMPETÊNCIA - MENOR - AUTORIZAÇÃO PARA TRABALHO EXTERNO - A autorização para que o menor faça trabalho externo deve ser requerida ao juiz da infância e da juventude nos termos do artigo 406 da CLT. ${ }^{14}$

CONSTITUCIONAL E PROCESSUAL CIVIL - ALVARÁ JUDICIAL PARA AUTORIZAÇÃO DE TRABALHO REMUNERADO POR MENOR DE 18 (DEZOITO) ANOS - PROCEDIMENTO ESPECIAL DE JURISDIÇÃO VOLUNTÁRIA - COMPETÊNCIA DA JUSTIÇA ESTADUAL SUPERVENIENTE PERDA DO OBJETO - EXTINÇÃO DO PROCESSO SEM JULGAMENTO DO MÉRITO - ART. 267, VI, DO CPC - 1. Tratando-se a espécie de alvará judicial para autorização de trabalho remunerado por menor de 18 (dezoito) anos, com a competente expedição de Carteira de Trabalho e Previdência Social-CTPS, a competência para processar e julgar o feito é da

\footnotetext{
${ }^{13}$ As alíneas "a” e "b” do § $3^{\circ}$ do art. 405 da CLT preveem como prejudiciais à formação moral do menor as seguintes atividades: serviços prestados de qualquer modo em teatros de revista, cinemas, boates, cassinos, cabarés, dancings e estabelecimentos análogos, em empresas circenses, em funções de acrobata, saltimbanco, ginasta e outras semelhantes.

${ }^{14}$ STJ; CC 28968; BA; Segunda Seção; Rel. Min. Ari Pargendler; Julg. 24.05.2000; DJU 1.08.2000; p. 00187.
} 
Justiça Comum, nos termos do art. 405, § $2^{\circ}$ e art. 406, ambos da CLT, ainda que a União Federal demonstre interesse na causa. Precedentes desta Corte... ${ }^{15}$

PROCEDIMENTO DE JURISDIÇÃO VOLUNTÁRIA AUTORIZAÇÃO PARA TRABALHAR - MENOR - COMPETÊNCIA DA JUSTIÇA COMUM - PERDA DO OBJETO - 1. A questão afeta à autorização para menor desempenhar atividade laborativa é da competência da Justiça da Infância e da Juventude, em conformidade com os artigos 405 e 406 da CLT c/c artigo 148, IV, da Lei no 8.069/90. 2. Compete à Justiça Estadual processar o pedido de alvará para o exercício de trabalho remunerado por menor de 16 anos, ainda que a União intervenha no feito, posto que o artigo 109, I, da CF somente tem aplicabilidade quando presente a litigiosidade inerente aos feitos de natureza contenciosa, não se estendendo aos procedimentos de jurisdição voluntária, onde não existe a figura de autor, réu, assistente ou oponente, subsistindo, apenas, participantes/interessados... ${ }^{16}$ (Sic)

Quanto ao segundo elemento essencial à formação do contrato de trabalho, qual seja a licitude do objeto, temos que nenhuma pessoa, tampouco o menor poderá ser contratado para trabalhar com atividade que contenha objeto ilícito. A Orientação Jurisprudencial n 199 , da primeira Seção de Dissídios Individuais, dispõe que "Jogo do bicho. Contrato trabalho. Nulidade. Objeto ilícito [...]”.

Já o terceiro elemento essencial à formação do contrato de trabalho diz respeito à forma regular ou não proibida em lei, ou seja, neste caso não se pode confundir ilícito com irregular: o ilícito compõe um tipo penal, enquanto o irregular ou proibido fere a norma.

Um exemplo clássico de contrato de trabalho proibido por lei é justamente o que diz respeito à vedação legal ao trabalho noturno, perigoso ou insalubre a menores de 18 anos (art. $7^{\circ}$, XXXIII da CF), o que infelizmente também é uma prática constante no dia a dia da população mais carente do Brasil.

\section{OS PROBLEMAS SOCIOECONÔMICOS E A EXPLORAÇÃO DO TRABALHO INFANTIL}

O Brasil, um País com dimensões continentais, padece do grande mal da sociedade capitalista pós-moderna, que infelizmente vive a busca do capital a qualquer preço, em virtude do fato de que a forma que as pessoas têm para alcançarem os bens materiais que anseiam ocorre somente com o acúmulo de capital.

Diante dessa situação real ocorrem as mais cruéis formas de exploração do ser humano, visando prioritariamente o lucro e que destroem a dignidade da pessoa humana. Um exemplo atual e cruel de exploração do ser humano é a prática de utilização do trabalho escravo ou análogo à escravidão, que pode se observado no Brasil e no mundo. Em um País onde grande parte da população vive sem sequer

\footnotetext{
${ }^{15}$ TRF $1^{\text {a }}$ R.; AC 2002.01.99.018390-4; MG; Sexta Turma; Rel. Juiz Fed. Conv. Moacir Ferreira Ramos; Julg. 20.07.2007; DJU 03.09.2007; p. 166.

${ }^{16}$ TJMG; AC 1.0166.03.002472-2/001; Cláudio; Oitava Câmara Cível; Rel. Des. Silas Rodrigues Vieira; Julg. 20.11.2003; DJMG 19.05.2004.
} 
saber como irá se alimentar no dia que estão vivendo, é extremamente complexo tratar do tema justiça social.

No caso da exploração do trabalho de crianças e adolescentes, a situação se agrava ainda mais, pois além da inobservância de preservação da sua dignidade, trata-se de indivíduos que estão em pleno desenvolvimento físico e emocional, que incontestavelmente irão sofrer sérias consequências pelo desrespeito aos seus direitos básicos.

Apesar de o Brasil possuir uma legislação protetora das crianças e adolescentes extremamente bem elaborada, percebe-se uma realidade social incongruente com os princípios fundamentais de proteção desse grupo social. É comum assistirmos diariamente o sofrimento de crianças e jovens que são explorados diante de nossos olhos nos semáforos das grandes cidades, nos grandes latifúndios ou até mesmo em locais de prostituição.

Rizatto Nunes relata, com propriedade, a dificuldade de se garantir a dignidade e o conflito entre interesses e direitos:

É inexorável: no meio social, como decorrência da garantia da dignidade a todas as pessoas e tendo em vista a natural colisão de interesses e direitos, ocorrerá, no limite, o embate entre dignidades ${ }^{17}$.

Infelizmente, na ânsia de satisfazer os interesses pessoais, muitas vezes se viola os direitos humanos fundamentais das pessoas que possuem menor conhecimento ou que sequer possuem condição de lutar por seus direitos. Essa realidade, por vezes, beira o caos social e traz como consequências as injustiças sociais, privando nossas crianças e adolescentes de direitos como acesso ao sistema de ensino, ao esporte, ao lazer, à saúde, ao convívio social e familiar, à cultura, à profissionalização, todos previstos na Constituição Federal e no ECA.

O professor Alexandre Moraes conceitua os direitos humanos fundamentais como o conjunto institucionalizado de direitos e garantias do ser humano que tem por finalidade básica o respeito à sua dignidade, por meio de sua proteção contra o arbítrio do poder estatal e o estabelecimento de condições mínimas de vida e desenvolvimento da personalidade humana ${ }^{18}$.

Não há dúvidas que é dever do Estado garantir o máximo possível de justiça social e consequentemente resguardar ao cidadão o conjunto de direitos humanos que, por sua vez, envolve uma série de direitos interligados, conforme bem asseverado por Marcos Francisco Reimann:

Os direitos humanos, entretanto, não existem dissociados. Estão todos interligados, civis, políticos, econômicos, sociais e culturais. Na construção da cidadania que, em nossa visão, é essencial para o desenvolvimento, assim,

17 NUNES, Luiz Antônio Rizzato. O Princípio Constitucional da Dignidade da Pessoa Humana. São Paulo: Saraiva, 2002, p. 56.

${ }^{18}$ MORAES, Alexandre de. Direitos Humanos Fundamentais. 6. ed., São Paulo: Atlas, 2005, p. 21. 
como deve ser uma decorrência natural dele, caminham juntos, interligam-se, combinam-se, complementam-se, etc. ${ }^{19}$.

O que se percebe é que jamais se alcançará a plenitude dos direitos humanos, enquanto a sociedade não se conscientizar de que essa exploração de crianças e jovens trará consequências nefastas ao futuro da humanidade que vão desde uma sociedade mais violenta até uma sociedade extremamente despreparada para enfrentar os problemas da humanidade que certamente estarão cada vez mais complexos.

Problemas sociais e econômicos não podem, em hipótese alguma, servir de argumentos para o desrespeito aos direitos humanos fundamentais de qualquer ser humano e tampouco das crianças e dos adolescentes. A garantia dos direitos humanos fundamentais é inerente ao regime democrático. Onde não se respeita os direitos humanos fundamentais não se pode dizer que há uma democracia plena, pois para que haja a paz social, deverá sempre haver a observância dos pilares da democracia.

4. A ATUAÇÃo DA OIT E DO BRASIL QUANTO AO TRABALHO INFANTIL

A Organização Internacional do Trabalho-OIT foi criada pela Conferência de Paz após a Primeira Guerra Mundial e sua constituição converteu-se na parte XIII do Tratado de Versalhes. Seu princípio fundamental é de que a paz universal e permanente só pode basear-se na justiça social.

A OIT é a estrutura internacional que torna possível abordar questões relacionadas aos direitos sociais do ser humano e buscar soluções que permitam a melhoria das condições de trabalho no mundo, sendo indubitavelmente fonte de importantes conquistas sociais que caracterizam a sociedade produtiva. Desde a sua criação, uma das maiores preocupações é com a questão da exploração do trabalho infantil. Segundo o professor Oris de Oliveira ${ }^{20}$, a OIT possui sessenta e uma convenções e recomendações relacionadas ao trabalho da criança e do adolescente.

A Convenção no 138, de $1973^{21}$, é chamada de "Convenção sobre Idade Mínima, de 1973”, e estipula no art. $2^{\circ}$ a idade mínima para o ingresso em qualquer emprego, que é de 15 anos de idade e, em casos específicos, após consulta às organizações de empregadores e de trabalhadores interessadas, se as houver, poderá se definir inicialmente uma idade mínima de 14 anos.

Entretanto, antes mesmo de dispor sobre a idade mínima para o trabalho do menor, a preocupação primária é com a erradicação do trabalho infantil, conforme se verifica no art. $1^{\circ}$ da referida Convenção, que assim dispõe:

Todo Estado-membro, no qual vigore esta Convenção, compromete-se a seguir uma política nacional que assegure a efetiva abolição do trabalho infantil e eleve, progressivamente, a idade mínima de admissão a emprego ou a trabalho a um nível adequado ao pleno desenvolvimento físico e mental do jovem.

${ }^{19}$ REIMANN, Marcos Francisco. Cidadania e contratos atípicos de trabalho: as políticas sociais e o ordenamento do trabalho. Porto Alegre: Sergio Antonio Fabris Editor, 2002, p. 120.

${ }^{20}$ OLIVEIRA, Oris de. O Trabalho da Criança e do Adolescente. São Paulo: LTr, 1994, pp. 43-61.

${ }^{21}$ A Convenção n ${ }^{\circ} 138$ de 1973 entrou em vigor em 19 de junho de 1973. 
A Recomendação $n^{\circ} 146$ da OIT também versa sobre a idade mínima para o ingresso no trabalho do menor, além de servir de suplemento à Convenção sobre Idade Mínima de 1973.

O Brasil promulgou a Convenção $n^{0} 138$ e a Recomendação $n^{\circ} 146$ da OIT em 15 de fevereiro de 2002, por meio do Decreto $n^{\circ} 4.134$, que entrou em vigor a partir de 28 de junho de 2002.

Em 1992, a OIT implementou mundialmente o Programa Internacional para Eliminação do Trabalho Infantil-IPEC -, que visa eliminar o trabalho infantil consolidando estratégias de cooperação e potencialização de ações em defesa dos direitos das crianças e dos adolescentes.

Na sequência desse trabalho de eliminação do trabalho infantil, em 17 de junho de 1999, foi aprovada a Convenção no 182 da OIT, que é chamada de "Convenção sobre as piores formas de trabalho infantil, de 1999”, que dispõe no art. $3^{\circ}$ o seguinte:

Art. $3^{\circ}$ Para efeitos da presente Convenção, a expressão “as piores formas de trabalho infantil” abrange:

a) todas as formas de escravidão ou práticas análogas à escravidão, tais como a venda e tráfico de crianças, a servidão por dívida e a condição de servo, e o trabalho forçado ou obrigatório de crianças para serem utilizadas em conflitos armados;

b) a utilização, o recrutamento ou a oferta de crianças para a prostituição, a produção de pornografia ou atuações pornográficas;

c) a utilização, recrutamento ou a oferta de crianças para a realização de atividades ilícitas, em particular a produção e o tráfico de entorpecentes, tais como definidos nos tratados internacionais pertinentes;

d) o trabalho que, por sua natureza ou pelas condições em que é realizado, é suscetível de prejudicar a saúde, a segurança ou a moral das crianças.

O suplemento da Convenção n ${ }^{\circ} 182$ da OIT é a Recomendação n 190 , ambas promulgadas pelo Brasil em 12 de setembro de 2000, por meio do Decreto $n^{\circ} 3.597$ e regulamentadas pelo Decreto $\mathrm{n}^{\circ}$ 6.481, de 12 de junho de 2008. Este último dispõe de uma lista com 89 formas de trabalho classificadas como as piores formas de trabalho infantil e mais quatro tipos de trabalho classificados como prejudiciais à moralidade do menor.

Desde 1992, quando a OIT implementou o IPEC, o Brasil vem contribuindo para esse objetivo, tendo iniciado um processo de articulação, mobilização e legitimação das iniciativas nacionais de combate ao trabalho infantil. Em 1996, foi criado, no Brasil, o Programa de Erradicação do Trabalho Infantil-PETI - que compõe o Sistema Único de Assistência Social - Suas com duas ações articuladas: o Serviço Socioeducativo ofertado para as crianças e adolescentes afastadas do trabalho precoce e a Transferência de Renda para suas famílias. Além de prever ações socioassistenciais com foco na família, potencializando sua função protetiva e os vínculos familiares e comunitários ${ }^{22}$.

22 Disponível em <http://www.mds.gov.br/programas/rede-suas/protecao-social-especial/programa-deerradicacao-do-trabalho-infantil-peti> Acesso em: 28 jul. 2009. 
O PETI está vinculado ao Ministério do Desenvolvimento Social e Combate à Fome e seu objetivo é contribuir para a erradicação de todas as formas de trabalho infantil no País, disponibilizando atendimento às famílias que tenham crianças e adolescentes com idade inferior a 16 anos que estejam exercendo algum tipo de trabalho. O Programa visa também o resgate da cidadania e promoção de direitos de seus usuários, bem como de inclusão social de suas famílias.

Segundo dados do IBGE $^{23}$ divulgados na Comunicação Social de 28 de março de 2008, a Pesquisa Nacional por Amostra de Domicílios - PNAD 2006 informa que 1,4 milhão de crianças brasileiras de 5 a 13 anos de idade trabalhava naquele ano, sendo que $62,6 \%$ dessas crianças trabalhavam em atividades agrícolas. No mesmo ano, 5,1 milhões de crianças e adolescentes de 5 a 17 anos de idade também estavam trabalhando. As informações demonstram ainda que 47,3\% das crianças e adolescentes que trabalham não recebem por isso.

Contudo, apesar dos altos índices de crianças e adolescentes que ainda se encontram trabalhando, observa-se que o PETI vem surtindo efeitos gradativos na sociedade brasileira, pois de acordo com o PNAD 2003, neste ano eram 2,7 milhões, na faixa dos 5 a 15 anos de idade. Em 1995, um ano antes da criação do PETI, eram 5,1 milhões de crianças entre 5 e 15 anos. Esta evolução vai ao encontro do que foi abordado no início do presente trabalho, onde se discutiu que somente políticas públicas sérias poderão mudar a situação atual das crianças e adolescentes carentes de nosso País.

\section{ATRIBUIÇÕES E ATUAÇÃO ADMINISTRATIVA DO MINISTÉRIO PÚBLICO EM RELAÇÃO À PROTEÇÃO A CRIANÇAS E ADOLESCENTES}

Conforme previsão no art. 127 da Constituição Federal, o Ministério Público é instituição permanente, essencial à função jurisdicional do Estado, incumbindo-lhe a defesa da ordem jurídica, do regime democrático e dos interesses sociais e individuais indisponíveis. Galdino Bordallo disserta que a atuação do Promotor de Justiça da Infância e Juventude é uma das mais diversificadas e gratificantes dentre as especializações funcionais do Ministério Público ${ }^{24}$.

Além da previsão constitucional de atuação do Ministério Público ora abordada, há também que se ressaltar as atribuições específicas do Ministério Público do Trabalho previstas no já mencionado art. 201 do ECA.

O Ministério Público do Trabalho é um órgão de fundamental importância na luta pela erradicação do trabalho infantil no Brasil, pois além do poder de fiscalizar tem competência para demandar por meio de ações coletivas em busca da justiça social. Sua atuação na Erradicação do Trabalho Infantil e Regularização do Trabalho do Adolescente toma por base uma série de dispositivos contidos na Constituição Federal, na Consolidação das Leis do Trabalho e legislação trabalhista, no ECA e em normas internacionais como as Convenções 138 e 182 da OIT e a Convenção dos Direitos da Criança da $\mathrm{ONU}^{25}$.

${ }^{23}$ Disponível em http://www.ibge.gov.br Acesso em: 28 jul. 2009.

${ }^{24}$ BORDALLO. Galdino Augusto Coelho. Curso de Direito da Criança e do Adolescente, apectos teoricos e práticos. 3. ed., Rio de Janriro: Lumen Juris, 2009, p. 381.

${ }^{25}$ Disponível em http://www.pgt.mpt.gov.br/pgtgc/publicacao/engine.wsp?tmp.area=286 Acesso em: 28 jul. 2009. 
As atribuições do Ministério Público do Trabalho estão dispostas no art. 83 da Lei Complementar 75, de 20 de maio de 1993, sendo que em relação aos direitos e interesses dos menores, há que se observar o inciso V do referido artigo:

Art. 83. Compete ao Ministério Público do Trabalho o exercício das seguintes atribuições junto aos órgãos da Justiça do Trabalho:

[...]

$\mathrm{V}$ - propor as ações necessárias à defesa dos direitos e interesses dos menores, incapazes e índios, decorrentes das relações de trabalho;

O Ministério Público do Trabalho mantém a Coordenadoria Nacional de Combate à Exploração do Trabalho da Criança e do Adolescente - Coordinfância, que atua na fiscalização de atividades ilícitas, trabalho doméstico, lixões, regularização do trabalho do adolescente, além de orientar e esclarecer as famílias sobre suas responsabilidades e o dever de agir rapidamente diante de situações que configurem exploração ou risco para preservar os direitos das crianças e dos adolescentes.

\section{CONCRETOS}

6. ATUAÇÃO DO MINISTÉRIO PÚBLICO DO TRABALHO EM CASOS

Nossa realidade hodierna demonstra que alguns grupos de pessoas - mulheres, idosos, portadores de deficiências, crianças e adolescentes - sofrem mais com as desigualdades sociais do mundo moderno. Diante disso, surgiram as chamadas "ações afirmativas” que, em suma, visam garantir direitos de forma não discriminatória a essas pessoas.

A Convenção $n^{\circ} 111$ da OIT, ratificada pelo Brasil em 1965, faz distinção entre discriminação e ação afirmativa, assunto que Oris de Oliveira aborda com propriedade, da seguinte maneira:

[...] não são discriminatórias as medidas especiais de proteção, destinadas a atender a necessidades particulares de pessoas que, por razão de sexo, idade, invalidez, encargos familiares, nível social ou cultural, tenham necessidade de proteção ou assistência especial ${ }^{26}$.

A Ação Civil Pública-ACP é o instrumento mais utilizado pelo Ministério Público do Trabalho para buscar a tutela jurisdicional dos direitos das crianças e adolescentes e assim evitar a exclusão dessa camada da sociedade dos direitos e garantias sociais previstas constitucionalmente em nosso País. Há uma discussão quanto a sua utilização para pleitear direitos individuais de crianças e adolescentes. Ainda assim, o aperfeiçoamento da legislação, bem como a doutrina e a jurisprudência vêm eliminando essa discussão, no sentido da possibilidade da propositura de ACP, ainda que em busca de direitos individuais.

Neste sentido, o professor Mazzilli tece interessantes comentários sobre o assunto, versando sobre a questão dos legitimados para propositura da ACP, bem como da possibilidade dela mesma em caso de tutela de direitos individuais:

${ }^{26}$ OLIVEIRA, Oris de. Trabalho e Profissionalização do Jovem. São Paulo: LTr, 2004. p. 100. 
À vista dos bons frutos da Lei da Ação Civil Pública, a Constituição de 1988 não só ampliou o rol dos legitimados para a defesa dos interesses transindividuais, como ainda alargou as hipóteses de cabimento da sua tutela judicial. Desta forma, para a tutela dos interesses ligados à proteção da criança, não é o Ministério Público o único legitimado ativo, nem o rol de interesses transindividuais é taxativo.

$[\ldots]$

Tratando-se de interesses indisponíveis de crianças ou adolescentes (ainda que individuais), e mesmo de interesses coletivos ou difusos relacionados com a infância e a juventude - sua defesa sempre convirá à coletividade como um todo.

Confere a Lei $n^{\circ}$ 8.069/90 iniciativa ao Ministério Público para a ação civil pública, na área da infância e da juventude, até mesmo no tocante à defesa de interesses individuais, dado seu caráter de indisponibilidade ${ }^{27}$.

O Superior Tribunal de Justiça tem decidido reiteradamente nesse mesmo sentido, conforme pode se verificar em algumas decisões envolvendo direito de crianças e adolescentes:

ADMINISTRATIVO - SISTEMA ÚNICO DE SAÚDE-SUS - AÇÃO CIVIL PÚBLICA - GARANTIA DE TRATAMENTO MÉDICO MENOR DIREITOS INDIVIDUAIS INDISPONÍVEIS - LEGITIMAÇÃO EXTRAORDINÁRIA DO PARQUET - A Primeira Seção desta Corte tem entendimento, já reiterado, no sentido de que o Ministério Público detém legitimidade para promover, com base no Estatuto da Criança e do Adolescente (Lei no 8.069/90), mediante ação civil pública, a tutela dos direitos indisponíveis nele previstos, mesmo que se apresentem como interesse individual. Precedentes. Agravo regimental improvido. ${ }^{28}$

PROCESSO CIVIL - AÇÃO CIVIL PÚBLICA VISANDO A GARANTIR ATENDIMENTO EM CRECHE A DUAS CRIANÇAS MENORES DE SEIS ANOS - DIREITOS INDISPONÍVEIS - LEGITIMAÇÃO ATIVA DO MINISTÉRIO PÚBLICO - I - A Primeira Seção desta Corte tem entendimento, já reiterado, no sentido de que o Ministério Público detém legitimidade para promover, com base no Estatuto da Criança e do Adolescente (Lei $n^{\circ}$ 8.069/90), mediante ação civil pública, a tutela dos direitos indisponíveis nele previstos, mesmo que se apresentem como interesse individual. Precedentes: ERESP 466861/SP, Rel. Ministro TEORI ALBINO ZAVASCKI, PRIMEIRA SEÇÃO, julgado em 28.03.2007, DJ 7.05.2007; ERESP 684.162/RS, Rel. Ministra DENISE ARRUDA, PRIMEIRA SEÇÃO, julgado em 24.10.2007, DJ 26.11.2007; ERESP 684.594/RS, Rel. Ministra

\footnotetext{
${ }^{27}$ MAZZILLI, Hugo Nigro. A defesa dos interesses difusos em juízo. 20. ed., São Paulo: Saraiva, 2007, p. 618. O professor Mazzilli menciona que diante desta disposição legal, o Ministério Público poderá ingressar com a Ação Civil Pública para assegurar vaga em uma escola tanto para uma criança, como para dezenas, centenas ou milhares delas.

${ }^{28}$ STJ; AgRg-REsp 1.075.336; Proc. 2008/0161851-4; RJ; Segunda Turma; Rel. Min. Humberto Martins; Julg. 18.12.2008; DJE 16.02.2009.
} 
Ultrapassada a discussão sobre a legitimidade do Ministério Público do Trabalho para pleitear direitos individuais de crianças e adolescentes, por meio de ACP, faz-se imprescindível observar o que tem ocorrido, na prática, em relação à exploração das mais variadas formas do trabalho infantil. O que se percebe é que, em alguns casos, empresas e órgãos ditos de encaminhamentos de jovens ao primeiro emprego têm-se utilizado de formas inescrupulosas de explorar disfarçadamente a mão de obra infantil, o que tem como consequência principal a extirpação dos direitos sociais dessas crianças e adolescentes.

Essas condutas são verificadas, na maioria dos casos, em virtude de que, por meio da exploração do trabalho infantil, consegue-se um trabalho com mão de obra extremamente menos onerosa, além de se tentar burlar com isso a legislação trabalhista, previdenciária e tributária.

Neste sentido, novamente se torna crucial atuação do Ministério Público do Trabalho, conforme se percebe no caso em que uma empresa situada na cidade de Ribeirão Pires, no interior do Estado de São Paulo, foi condenada pela Primeira Turma do Tribunal Superior do Trabalho a reconhecer vínculo de emprego a trinta crianças e adolescentes com idade entre 10 e 14 anos, que trabalhavam como guardas mirins.

De acordo com o Ministério Público do Trabalho ${ }^{30}$, os menores eram submetidos a um curso de 90 dias e, após a conclusão, eram colocados para trabalhar em empresas da região, pelo período de quatro horas diárias, recebendo R\$ 65,00 mensais a título de remuneração, sendo que desse total, $\mathrm{R} \$ 26,00$ ficavam retidos na entidade.

Ficou decidido na ação que os menores teriam todos os direitos trabalhistas, como complementação salarial, $13^{\circ}$ salário, FGTS, verbas rescisórias, férias vencidas e proporcionais, sendo que aos maiores de 14 anos foi também garantido o direito a anotação na CTPS.

Diante do exposto, é oportuno observar a ementa do acordão que julgou o caso em comento:

AÇÃO CIVIL PÚBLICA - MINISTÉRIO PÚBLICO DO TRABALHO - LEGITIMIDADE ATIVA - DIREITOS INDIVIDUAIS HOMOGÊNEOS INTERESSES RELATIVOS À CRIANÇA E AO ADOLESCENTE Tem legitimidade o Ministério Público do Trabalho para propor ação civil pública, visando tutelar direitos em favor das crianças e adolescentes. Tal é a hipótese sob exame, em que o Parquet Trabalhista persegue a condenação da reclamada, ante a constatação por Inquérito Civil Público da utilização ilegal de mão-de-obra infantil. A legitimidade alcança os direitos individuais homogêneos,

\footnotetext{
${ }^{29}$ STJ; EREsp 488.427; Proc. 2007/0213426-2; SP; Primeira Seção; Rel. Min. Francisco Cândido de Melo Falcão Neto; Julg. 10.09.2008; DJE 29.09.2008.

${ }^{30}$ Disponível em <http://ext02.tst.jus.br/pls/no01/NO_NOTICIASNOVO.Busca> Acesso em: 28 jul. 2009.
} 
que, na dicção da jurisprudência corrente do Excelso Supremo Tribunal Federal, nada mais são senão direitos coletivos em sentido lato, uma vez que todas as formas de direitos metaindividuais (difusos, coletivos e individuais homogêneos), passíveis de tutela mediante ação civil pública, são coletivos. Imperioso observar, apenas, em razão do disposto no artigo 127 da Constituição Federal, que o direito individual homogêneo a ser tutelado deve revestir-se do caráter de indisponibilidade. Exegese do artigo $6^{\circ}$, VII, letras c e d, da Lei Complementar $\mathrm{n}^{\circ}$ 75/93. Recurso de revista não conhecido. RECONHECIMENTO DE VÍNCULO DE EMPREGO. GUARDA MIRIM. É insuscetível de revisão, em sede extraordinária, decisão proferida pelo Tribunal Regional à luz da prova carreada aos autos. Somente com o revolvimento do substrato fático probatório seria possível afastar a premissa sobre a qual se erigiu a conclusão de que estavam presentes os pressupostos de uma relação de emprego. Hipótese de incidência da Súmula $n^{\circ} 126$ do Tribunal Superior do Trabalho. Recurso de revista não conhecido. ${ }^{31}$ (Sic)

Ainda neste sentido, uma decisão do Tribunal Regional do Trabalho da $15^{\text {a }}$ Região retrata, de forma exemplar, o que vem acontecendo na realidade do Brasil, em termos de evolução das políticas de proteção dos direitos humanos, inclusive dos direitos das crianças e dos adolescentes.

Contudo, o mesmo julgado relata também sobre essas entidades que se proliferam, até com boas intenções, mas que acabam fomentando de forma ilegal o trabalho infantil e realizando verdadeira intermediação de mão de obra, sob alegações de realizarem atividades filantrópicas e sociais, mas que infelizmente acabam por colocar esses menores no mercado de trabalho sem qualquer proteção e com total inobservância da legislação que tutela os direitos das crianças e dos adolescentes. Vejamos os principais pontos do acórdão:

AÇÃO CIVIL PÚBLICA - TRABALHO DA CRIANÇA E DO ADOLESCENTE - O Brasil, gradativamente, vem enquadrando-se na política internacional de proteção dos direitos humanos, inclusive dos direitos das crianças e adolescentes, tendo, para tanto, ratificado a Declaração dos Direitos da Criança, em 1959, e a Convenção sobre os Direitos da Criança, em 24.09.90. Na esteira da tendência dos debates internacionais, o Brasil fez incluir importantes dispositivos na CF/88, dentre os quais os arts. 203, 227 e 228. Ainda, foram promulgados o Estatuto da Criança e do Adolescente e a Lei $n^{\circ} 10.097 / 00$. Todo esse arcabouço jurídico enfatiza a concepção de que crianças e adolescentes devem ter resguardados a primazia na prestação de socorros, a precedência de atendimento nos serviços públicos, preferência na formulação e execução de políticas sociais e, por derradeiro, privilégio da destinação de recursos públicos para a proteção infanto-juvenil. $O$ estímulo à aprendizagem, em termos de formação técnico-profissional, subordina-se à garantia de acesso e freqüência obrigatória ao ensino regular por parte do adolescente. De conseqüência, proliferam entidades, ainda que com boas intenções, espalhando o trabalho infantil e realizando verdadeira intermediação

${ }^{31}$ TST; RR 334/1999-411-02-00.2; Primeira Turma; Rel. Min. Lélio Bentes Corrêa; DJU 06.09.2007; p. 781.

Direitos Fundamentals $\mathcal{E}$ Justiça N' 13 - OUt./Dez. 2010 
de mão-de-obra, sob os auspícios de realizarem atividades filantrópica $e$ social, reduzindo a incidência de menores de rua e de marginalidade infantil, encaminhando-os ao mercado de trabalho, sem qualquer proteção $e$ cumprimento desse arcabouço jurídico. O trabalho educativo é aquele em que a dimensão produtiva está subordinada à dimensão formativa. Distingue-se do trabalho stricto sensu, subordinado, por não restar configurada, precipuamente, a sua finalidade econômica e, sim, uma atividade laborativa, que se insira no contexto pedagógico, voltada mais ao desenvolvimento pessoal e social do educando. Não encontradas essas características, a entidade está descumprindo os ditames legais, devendo abster-se dessas práticas, pelo que tem pertinência a Ação Civil Pública. ${ }^{32}$ (Grifos meus)

O Ministério Público do Trabalho também tem agido no sentido de buscar a efetividade da legislação brasileira. Neste sentido, o art. 429 da CLT, com redação dada pela Lei $\mathrm{n}^{0}$ 10.097/00, dispõe sobre a obrigatoriedade das empresas contratarem aprendizes:

Art. 429. Os estabelecimentos de qualquer natureza são obrigados a empregar e matricular nos cursos dos Serviços Nacionais de Aprendizagem número de aprendizes equivalente a cinco por cento, no mínimo, e quinze por cento, no máximo, dos trabalhadores existentes em cada estabelecimento, cujas funções demandem formação profissional.

Diante do dispositivo legal em destaque e percebendo o não cumprimento da legislação vigente por empresas que obrigatoriamente se encaixam na mencionada disposição legal, o Ministério Público do Trabalho interpôs ACP pleiteando obrigação de fazer cumulada com indenização pós-danos morais, que foi aceita pelo Tribunal Regional do Trabalho da $17^{\text {a }}$ Região, conforme se verifica na decisão a seguir:

A - Impossibilidade jurídica do pedido. tutela coletiva. Impossível é o pedido vedado de forma expressa na Lei. Em sede de tutela coletiva, cabíveis são todas as pretensões, inclusive de cunho condenatório. Nesta diretriz, é possível, na ação civil pública, pedir a tutela de mais de um tipo de interesse transindividual, bem como acumular pedidos de obrigação de fazer e de pagar. B - Legitimidade do Ministério Público do Trabalho. Ação civil pública. A legitimidade extraordinária do Ministério Público para a tutela de interesses difusos e coletivos está prevista no art. $5^{\circ}$ da Lei $n^{\circ} 7.347 / 85$, posteriormente ampliada pelo art. 129 da Constituição da República. O Código de Defesa do Consumidor distinguiu os tipos de interesses e incluiu a tutela coletiva para os individuais homogêneos. C - Obrigação de fazer - Contratação e matrícula de aprendizes - Art. 429 da CLT. O oferecimento de oportunidades aos jovens aprendizes não é mera questão de "abrir vagas", mas o oferecimento de reais oportunidades, para construir uma percepção profissional ao menor, viabilizando projetos de vida para as novas gerações. O não oferecimento dessa oportunidade poderia acarretar um preço elevado. Não custa lembrar os custos referentes à violência, discriminação e insegurança social, que a sociedade brasileira está

${ }^{32}$ TRT 15ª R, Proc. 2136/02, Ac. 12795/02, 3ª T, Rel. Juiz Luciane Storel da Silva, DOESP 08.08.2002. 
suportando há muito tempo. A contratação de aprendizes é obrigação prevista na Consolidação das Leis Trabalhistas, Estatuto da Criança e do Adolescente e Decreto $\mathrm{n}^{\circ}$ 5.598/2005, que regulamentou a contratação de aprendizes. D - Dano moral coletivo. Qualquer abalo no patrimônio moral de uma coletividade também merece reparação. O tratamento transidividual aos chamados interesses difusos e coletivos origina-se justamente da importância destes interesses e da necessidade de uma efetiva tutela jurídica. Deixar de contratar aprendizes afeta toda a sociedade e afronta o princípio social da empresa. E - Ampliação dos efeitos da sentença. Os direitos difusos, notadamente aqueles relativos aos aprendizes, são indivisíveis com abrangência geral. $\mathrm{O}$ acesso efetivo e substancial à justiça ocorre com a universalização dos efeitos da sentença, compreendendo todos aqueles cujos direitos ou interesses foram atingidos; isso porque o caráter homogêneo do direito deve ser o critério determinante da amplitude da jurisdição e não a competência territorial do órgão julgador. O âmbito da abrangência da coisa julgada é determinado pelo pedido, e não pela competência, que diz respeito à relação de adequação entre o processo e o juiz..$^{33}$ (Sic)

Outra ACP interposta pelo Ministério Público do Trabalho que merece destaque foi fundamentada no Estatuto da Criança e do Adolescente, em virtude de descumprimento de termo de ajustamento de conduta. A empresa, que tinha praticado reiteradamente exploração do trabalho infanto-juvenil, havia ajustado com o Ministério Público do Trabalho em abster-se dessa prática ilegal, sob pena de multa pecuniária, conforme se verifica pela decisão em destaque:

AÇÃO CIVIL PÚBLICA - ESTATUTO DA CRIANÇA E DO ADOLESCENTE (LEI No 8.069/90) - Termo de ajustamento de conduta firmado entre a apelante e o ministério público. Compromisso de abster-se de explorar o trabalho infanto-juvenil. Descumprimento. Procedimento administrativo preliminar, instaurado pelo representante do parquet estadual, que apurou a reiteração da prática. Condenação em multa pecuniária. Alegação de não possuir condições em arcar com esta sanção. Irrelevância. Cominação que possuía previsão expressa no acordo firmado. Recurso desprovido. ${ }^{34}$ (Sic)

Um caso de notoriedade nacional que também foi alvo do Ministério Público do Trabalho foi a ação movida contra família Calabresi, do Estado de Goiás, acusada de explorar trabalho infantil em sua residência. Neste caso específico, o Ministério Público justificou a propositura da ACP em razão dos atos de "extrema violência, abusos, trabalho forçado, tortura e ameaças, bem como da gravíssima ofensa aos direitos humanos e à ordem jurídica" cometidos pelos membros da família contra a menor, que teria sido reduzida à condição de “coisa”.

A ACP cita, entre os atos de perversidade cometidos reiteradamente pela empregadora - uma empresária - contra a adolescente, o fato desta ter sido coagida a

${ }^{33}$ TRT $17^{\text {a }}$ R; RO 00073.2007.013.17.00.0; Ac. 694/2008; Rel. Juiz Cláudio Armando Couce de Menezes; DOES 07.02.2008; p. 12.

${ }^{34}$ TJSC; AC 2007.032001-3; Criciúma; Quarta Câmara de Direito Público; Rel. Des. José Volpato de Souza; DJSC 05.02.2009; p. 107. 
lamber urina do cachorro da casa e a comer o seu próprio vômito, causado pelo ato repugnante que estava sendo obrigada a fazer.

Na decisão proferida pela juíza da $10^{\mathrm{a}}$ Vara do Trabalho de Goiânia, o casal foi condenado a pagar R \$300.000,00 de indenização por danos morais e estéticos, além de verbas trabalhistas. O casal ainda foi condenado, na ACP, ao pagamento de R\$ 80 mil por danos morais coletivos.

Para julgar as ações, a magistrada concluiu que o trabalho prestado pela adolescente não se limitava ao auxílio nas tarefas domésticas, mas que ela realmente assumia as obrigações como empregada da família ${ }^{35}$.

\section{CONCLUSÕES}

Verifica-se que a exploração do trabalho infantil é um problema social antigo, que somente poderá ser solucionado com atuação plena do governo, da sociedade e das instituições que detêm o poder para mudar esta situação, por meio de ações concretas que venham efetivamente punir as pessoas que utilizam dessa prática de exploração deplorável.

O governo deve investir em mais políticas públicas de incentivo ao combate ao trabalho infantil, como por exemplo o PETI-Programa de Erradicação do Trabalho Infantil, que oferece condições de recolocar o menor que esteja trabalhando em atividades coerentes com sua condição especial (escola, atividades esportivas, culturais e sociais).

A sociedade, por sua vez, deve agir de modo a não aceitar esse tipo de exploração que ocorre às claras nesse mundo moderno, onde o capitalismo tem imperado sem a menor observância aos direitos básicos e essenciais do ser humano.

As instituições que detêm o poder, como o Judiciário e órgãos independentes como o Ministério Público do Trabalho, devem fiscalizar e operar fazendo cumprir as normas de proteção das crianças e adolescentes.

A evolução da legislação no sentido de proteção à criança e o adolescente, tem contribuído sobremaneira para a diminuição da exploração do trabalho infantil no Brasil, a se destacar o advento da Constituição Federal de 1988, do Estatuto da Criança e do Adolescente em 1990 e de leis como a Lei 10.097/00, que dispõe sobre o trabalho do aprendiz.

Percebe-se o quão é crescente as demandas no Judiciário, visando não só a proteção dos direitos difusos e coletivos, como também dos direitos indivuduais homogêneos, visto ser patente a necessidade de salvaguardar situações específicas relacionadas a crianças e adolescentes, mas, que indubitavelmente tem grande impacto jurídico e social.

As Ações Civis Públicas têm sido a grande arma para fazer cumprir as normas de proteção e segurança dedicadas às crianças e adolescentes. Por meio dessas ações, o Judiciário tem demonstrado em suas decisões, sua intolerência a condutas de abuso e exploração ao trabalho infantil, com condenações de cunho material e extrapatrimonial, que de certa forma tem obtido um resultado educacional, na medida que disperta no

${ }^{35}$ Disponível em <http://veja.abril.com.br/121108/p_118.shtml> Acesso em: 28 jul. 2009. 
explorador a sensação de risco de punibilidade e com isso tem conseguido paulatinamente alcançar o objetivo previsto em nossa legislação que norteia o tema.

Diante disso, um contrato ilegal de trabalho infantil, que outrora era considerado lucrativo para o empregador em virtude da sonegação dos encargos sociais e da impunibilidade, passa a ser um contrato desinteressante, tendo em vista um risco iminente de prejuízo fianceiro, além de eventuais consequências relacionadas a imagem de "mau empregador" perante sociedade em geral.

Assim, nota-se que a justiça social contemplada em nossa Carta Magna somente será alcançada em relação às crianças e adolescentes com ações conjuntas na sociedade, que serão imprescindíveis para que nossas crianças e adolescentes possam viver em condições dignas.

\section{BIBLIOGRAFIA}

BONAVIDES, Paulo. Curso de Direito Constitucional. 11. ed., São Paulo: Malheiros, 2001.

BORDALLO. Galdino Augusto Coelho. Curso de Direito da Criança e do Adolescente, aspectos teóricos e práticos. 3. ed., Rio de Janeiro: Lumen Juris, 2009.

CANOTILHO, José Joaquim Gomes. Direito Constitucional e Teoria da Constituição. 5. ed., Coimbra: Almedina, 2002.

CANOTILHO, José Joaquim Gomes. Tomemos a sério os direitos econômicos, sociais e culturais. Boletim da Faculdade de Direito. Coimbra: Universidade de Coimbra, nº. esp., 1991.

COMPARATO, Fábio Konder. O Ministério Público na defesa dos direitos econômicos, sociais e culturais. Revista da Faculdade de Direito da Universidade Federal de Minas Gerais. Belo Horizonte: UFMG, nº 40, jul./dez. 2001.

CUPIS, Adriano de. Os Direitos da Personalidade. Trad. Afonso Celso Furtado Rezende. Campinas: Romana Jurídica, 2004.

DELGADO, Maurício Godinho. Capitalismo, Trabalho e Emprego. São Paulo: LTr, 2007.

DINIZ, Maria Helena. Norma Constitucional e seus Efeitos. 7. ed., São Paulo: Saraiva, 2006.

DONATO, Messias Pereira. Processo e formação histórica do direito do trabalho. In MALLET, Estêvão; ROBORTELLA, Luiz Carlos Amorin (Coords.). Direito e Processo do Trabalho estudos em homenagem a Octavio Bueno Magano. São Paulo: LTr, 1996.

FERREIRA FILHO, Manoel Gonçalves. Os direitos fundamentais. Problemas jurídicos, particularmente em face da Constituição Brasileira de 1988. Revista de Direito Administrativo. Rio de Janeiro: Renovar, nº 203, jan./mar. 1996.

JOÃO, Paulo Sergio. As questões trabalhistas fundamentais. In: Antônio Carlos Kfouri Aidar. (Org.). Administração Rural. São Paulo: Paulicéia, 1995, p. 137-171.

KRELL, Andreas J. Direitos Sociais e Controle Judicial no Brasil e na Alemanha. Porto Alegre: Sérgio Antonio Fabris Editor, 2002.

LAKATOS, Eva Maria; MARCONI, Marina de Andrade. Fundamentos de Metodologia Científica. 4 ed. São Paulo: Atlas, 2001.

MARQUES, Rafael da Silva. Valor social do trabalho na ordem econômica, na Constituição Brasileira de 1988. São Paulo: LTr, 2007.

MAZZILLI, Hugo Nigro. A defesa dos interesses difusos em juízo. 20. ed., São Paulo: Saraiva, 2007.

Direitos Fundamentals $\mathcal{E}$ Justiça N' 13 - OUt./Dez. 2010 
MELLO, Celso Antonio Bandeira de. Eficácia das Normas Constitucionais e Direitos Sociais. São Paulo: Malheiros, 2009.

MINHARRO, Erotilde Ribeiro dos Santos. A Criança e o Adolescente do Direito do Trabalho. São Paulo: LTr, 2003.

MIRANDA, Jorge. Manual de Direito Constitucional. v. 4. Coimbra: Coimbra, 1998.

Os direitos fundamentais - sua dimensão individual e social. Cadernos de Direito

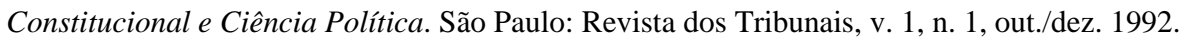

MORAES, Alexandre de. Direitos Humanos Fundamentais. 6. ed., São Paulo: Atlas, 2005.

NASCIMENTO, Amauri Mascaro. Curso de Direito do Trabalho. 21. ed., São Paulo: Saraiva, 2006.

NERY JUNIOR, Nelson; NERY, Rosa Maria de Andrade. Constituição Federal comentada e Legislação Constitucional. 2. ed., São Paulo: Revista dos Tribunais, 2009.

NUNES, Luiz Antônio Rizzato. O Princípio Constitucional da Dignidade da Pessoa Humana. São Paulo: Saraiva, 2002.

OLIVEIRA, Oris de. O Trabalho da Criança e do Adolescente. São Paulo: LTr, 1994.

Trabalho e Profissionalização do Jovem. São Paulo: LTr, 2004.

PAULA, Paulo Afonso Garrido de. Direito da Criança e do Adolescente e Tutela Jurisdicional diferenciada. São Paulo: RT, 2002.

REIMANN, Marcos Francisco. Cidadania e contratos atípicos de trabalho: as políticas sociais e o ordenamento do trabalho. Porto Alegre: Sergio Antonio Fabris Editor, 2002.

RODELLO, Fernanda Cavalcante Batista. A profissionalização do menor aprendiz e a sua inserção no mercado de trabalho. Síntese Trabalhista. v. 16, n. 188, fev. 2005.

RODRIGUEZ, Américo Plá. Princípios de Direito do Trabalho. 3 ed., São Paulo: LTr, 2000.

SANTOS, Enoque Ribeiro dos. Temas modernos de Direito do Trabalho. Leme: BH, 2005.

SARLET, Ingo Wolfgang. A Eficácia dos Direitos Fundamentais. 3. ed. rev. e atual., Porto Alegre: Livraria do Advogado, 2003.

SILVA, Walküre Lopes Ribeiro da. A teoria da justiça e o direito do trabalho. In CORREIA, Marcus Orione Gonçalves. (Coord.) Curso de Direito do Trabalho - teoria geral do Direito do Trabalho. v. I. São Paulo: LTr, 2007.

SOUZA, Letícia Godinho de. Direito do Trabalho, Justiça e Democracia. São Paulo: LTr, 2006. SOUZA JÚNIOR, Cezar Saldanha. Constituições do Brasil. Porto Alegre: Sagra Luzzatto, 2002.

VIANA, Cláudia Salles Vilela. Manual de Prática das Relações Trabalhistas. 5 ed., São Paulo: LTr, 2005.

WALDRAFF, Célio Horst. O liberalismo clássico, o neoliberalismo e o manifesto comunista. In Aldacy Rachid, COUTINHO; WALDRAFF, Célio Horst. Direito do Trabalho e Direito Processual do Trabalho - temas atuais. Curitiba: Juruá, 2000.

ZYLBERSTAJN, Hélio; PAGOTTO, Carmen Silva; PASTORE, José. A Mulher e o Menor na Força de Trabalho. São Paulo: Nobel, 1985. 